\title{
Evaluation and nonsurgical management of rotator cuff calcific tendinopathy.
}

\author{
Ari C. Greis \\ Rothman Institute, Thomas Jefferson University \\ Stephen M. Derrington \\ Rothman Institute, Thomas Jefferson University \\ Matthew McAuliffe \\ Rothman Institute, Thomas Jefferson University
}

Follow this and additional works at: https://jdc.jefferson.edu/rothman_institute

Part of the Orthopedics Commons

Let us know how access to this document benefits you

\section{Recommended Citation}

Greis, Ari C.; Derrington, Stephen M.; and McAuliffe, Matthew, "Evaluation and nonsurgical management of rotator cuff calcific tendinopathy." (2015). Rothman Institute Faculty Papers.

Paper 64.

https://jdc.jefferson.edu/rothman_institute/64

This Article is brought to you for free and open access by the Jefferson Digital Commons. The Jefferson Digital Commons is a service of Thomas Jefferson University's Center for Teaching and Learning (CTL). The Commons is a showcase for Jefferson books and journals, peer-reviewed scholarly publications, unique historical collections from the University archives, and teaching tools. The Jefferson Digital Commons allows researchers and interested readers anywhere in the world to learn about and keep up to date with Jefferson scholarship. This article has been accepted for inclusion in Rothman Institute Faculty Papers by an authorized administrator of the Jefferson Digital Commons. For more information, please contact: JeffersonDigitalCommons@jefferson.edu. 


\section{Evaluation \& Non-Surgical Management of Rotator Cuff Calcific Tendinopathy}

\section{Keywords}

Rotator Cuff, Calcific Tendinopathy, Shoulder Pain, Ultrasound, Aspiration, Lavage

\section{Synopsis}

Rotator cuff calcific tendinopathy (RCCT) is a common finding that accounts for about $7 \%$ of patients with shoulder pain. There are numerous theories on the pathogenesis of RCCT, all dealing with tendon injury and then subsequent calcium deposition that can then lead to tendonitis, subacromial impingement, and bursitis. The diagnosis is confirmed with x-ray, MRI or ultrasound. There are numerous conservative treatment options available and most patients can be managed successfully without surgical intervention. Nonsteroidal Anti-inflammatory Drugs (NSAIDs) and modalities are commonly used to manage pain and inflammation, whereas physical therapy can help improve scapular mechanics and decrease dynamic impingement of the calcific tendon in the subacromial space. Patients with ongoing pain may benefit from extracorporal shock wave therapy (ESWT) or injection therapy into the subacromial bursa or calcific tendon itself. Ultrasoundguided needle aspiration and lavage techniques have been shown to provide excellent long-term improvement in pain and function in patients with RCCT. 


\section{Key Points}

- Rotator cuff calcific tendinopathy is a common asymptomatic finding on imaging studies that accounts for shoulder pain approximately $7 \%$ of the time

- A majority of patients are managed conservatively with a combination of NSAIDs, modalities, physical therapy, and injection therapy

- The goal of physical therapy is to improve scapular mechanics and decrease subacromial impingement secondary to rotator cuff calcific tendinopathy

- Ultrasound guided needle aspiration and lavage of calcium deposits in the rotator cuff tendons has been shown to decrease the size of deposits and improve pain and function on a long-term basis

\section{Introduction}

Rotator cuff disease is a common cause of shoulder pain. The differential diagnosis of rotator cuff disease includes tendinitis, tendinopathy, subacromial impingement, partial and full thickness tendon tears, and calcific tendinopathy. Although calcific tendinopathy is a common incidental finding on imaging studies, it can also be a cause of significant shoulder pain and disability. The supraspinatus tendon is most commonly involved which can lead to significant subacromial impingement and limit activities at or above shoulder level. Like many other rotator cuff problems, a majority of patients respond well to relative rest, NSAIDs, physical therapy, and subacromial bursa injections with corticosteroids. There is growing interest and use of ultrasound guided injection procedures in musculoskeletal 
medicine. One novel technique for the treatment of RCCT involves advancing a larger gauge needle under live sonography into the calcium deposit, fragmenting it and aspirating its contents. This technique has been shown to provide excellent long-term pain relief and may be a good alternative to surgical intervention.

\section{Epidemiology}

There have been a number of studies on the epidemiology of RCCT. One of the most famous of these studies was done by Bosworth in 1941 who looked at 5,061 office employees and found the prevalence of calcium deposits in the rotator cuff to be $2.7 \%$ on fluoroscopic examination. ${ }^{1} \mathrm{~A}$ number of other studies have reported prevalence rates ranging from $2.7 \%$ to $22 \%$, mostly affecting people ranging from 30-50 years of age. ${ }^{1-3}$ It is often an asymptomatic finding on imaging studies. However, when considering people with shoulder pain, RCCT is a finding $6.8 \%$ of the time. ${ }^{4}$ When one shoulder is affected, the other shoulder will also be affected $14 \%$ of the time. ${ }^{7}$ Similar to other rotator cuff pathology, the supraspinatus tendon is most likely to be affected. ${ }^{3}$

People with sedentary lifestyles experience a higher risk of developing RCCT. ${ }^{4}$ Ischemic heart disease, hypertension, diabetes and thyroid disease are known associated medical conditions that seem to predispose patients to developing calcific tendinopathy for reasons not well understood. ${ }^{5}$ There is a known correlation with calcific tendinopathy and endocrine disorders. These patients have an earlier onset of symptoms, a longer disease course, and ultimately undergo surgery more frequently than people that do not have these conditions. ${ }^{6}$ 
Interestingly, RCCT is rarely associated with metabolic disorders related to calcium or phosphorus. ${ }^{7}$

\section{Pathophysiology}

The mechanism of the pathogenesis of calcific tendinopathy has remained elusive. There are several competing theories. It has been suggested that one of the reasons the pathogenesis remains unknown is that biopsies obtained are done near the end of the natural history of the disease. ${ }^{8,9}$ The four theories on the pathogenesis of calcific tendinopathy that will be discussed in this paper include degenerative calcification, reactive calcification, endochondral ossification and chondral metaplasia (Table 1).

In degenerative calcification it has been proposed that tendon fibers deteriorate over time. It is believed that aging tenocytes become progressively more damaged with time as a result of decreased vascular flow and tendon fibers become hypocellular and eventually undergo necrosis from the damage.3,10-12 As a result, intracellular calcium builds within the tenocytes in the form of psamomma bodies during the beginning phases of calcification. This in turn becomes larger over time until there are macroscopic areas of calcification that will be apparent on imaging and possibly symptomatic in affected patients. ${ }^{3,8,12}$

Reactive calcification proposes the cause of calcification is a multi-stage process beginning with tenocyte metaplasia which leads to calcification and ultimately a cell-mediated inflammatory reaction. ${ }^{9}$ Uhtoff et al proposed dividing the process into 3 main stages; precalcific, calcific, and post calcific (Table 2). ${ }^{9}$ In the precalcific stage the tenocytes undergo metaplasia into fibrocartilaginous tissue. 
This acts as a substrate for calcium deposition, which is believed to be mediated by chondrocytes $^{3,9}$. The calcific stage is when actual calcium deposition occurs in the tendon and the body's subsequent reaction to a calcified tendon. Uhtoff et al further subdivides the calcific stage into the formative and resorptive phases. In the formative phase, calcium crystals deposit into the affected tissue, which is mediated by the chondrocytes of the metaplastic fibrocartilagenous tissue, that eventually combine into larger areas of calcified tissue. Uhtoff further comments that if surgery is done during this stage of the disease the calcified areas will be chalky and need to be 'scooped' out. ${ }^{3}$ The resorptive phase begins after a varying period of dormancy in the disease course. The affected area develops 'vascular channels' where macrophages phagocytose and eliminate the calcium. ${ }^{3,9}$ Finally, the postcalcific phase describes the process where fibroblasts in granulation tissue remodel the affected tissue following calcium removal.,9

Another mechanism proposed by Benjamin et al, who studied Achilles tendons of rats, suggested that endochondral ossification of fibrocartilage is the pathogenesis of calcific tendinopathy. ${ }^{8,13}$ Again, fibrocartilage first develops in affected sites through the process of metaplasia. The fibrocartilage then develops vascular flow from underlying bone marrow. As the fibrocartilage becomes increasingly vascular, deposits of calcium form. ${ }^{13}$ What develops is essentially a bone spur in the tendon tissue. ${ }^{8,13}$ An important note, is that through this process no inflammatory reaction was seen to take place. ${ }^{13}$ Unfortunately, Benjamin et al did not report on the process of resorption and changes that take place in the rat tendons. 
The fourth mechanism discussed here is that of chondral metaplasia. Rui et al believes the calcification of tenocytes is a result of erroneous differentiation of tendon stem cells into bone cells. ${ }^{14}$ Hashimoto et al showed that injection of BMP-2 into tendons produced ectopic bone formation in the tendon suggesting tendon stem cells were responsive to proteins thought to induce bone growth.8,15 The exact mechanism by which tendon stem cells differentiate themselves incorrectly into bone is not clear at this point.

To complement the discussion, it has been proposed that there are genetic components that predispose certain populations to developing calcific tendinopathy. ${ }^{5}$ It should also be mentioned again that there are a number of endocrine and vascular disorders that are associated with calcific tendinopathy. However, it is not clear how they affect the natural history of the disease.

Although the exact mechanism of the pathophysiology remains elusive, there are a few important points to take into consideration:

- There are a number of things that likely contribute to the development of calcific tendinopathy

- There are a number of medical conditions that can predispose a person to this condition

- There may be a genetic component and familial predisposition

It is tempting to think there is some sort of injury that first occurs to the tendon cells, whether it's an acute clinically apparent injury or a series of subclinical microtraumas over the span of several years. Certainly, something must occur to 
induce metaplasia of the tenocytes that ultimately lead to the development of calcific tendinopathy. Furthermore, it is unclear if the calcification and resorption process is a part of normal healing that takes place in an injured tendon.

\section{Clinical presentation}

Calcific tendinopathy of the shoulder may present in a number of different ways, however the main complaint when patients are symptomatic will be pain. As

previously discussed, epidemiologic studies have shown that many cases of calcific tendinopathy of the shoulder will be asymptomatic or an incidental finding on imaging studies. However, Bosworth et al reported that $34-45 \%$ of patients with rotator cuff calcifications were found to be symptomatic. ${ }^{1}$

A good way to look at rotator cuff calcific tendinopathy, and its typical natural history, is that the disease progresses through 3 stages: the pre-calcification stage, the calcification stage, which includes the formative and resorptive phases, and the post-calcific stage (Table 2).

Often times the pain is worse in acute presentations than in chronic presentations. ${ }^{2,7}$ In some chronic forms there may be periods where patients are asymptomatic and a relapsing remitting pattern will be observed. ${ }^{2}$ Uhtoff et al and Speed et al have both commented that it is during the resorptive stage that patients are most likely to develop symptoms and this was attributed to the process of resorption of calcium itself., When osteolysis of the greater tuberosity is observed in calcific tendinopathy of the shoulder, it has been reported that there is an association with worse outcomes, more pain, more functional impairment and less success with surgery. ${ }^{16}$ In most cases, the pain and other symptoms will be self- 
limited and the natural history of the disease is for pain to improve over time without the need for aggressive interventions.

\section{History and Physical Examination}

A complete history is important when evaluating a patient with shoulder pain. Questions to ask relate to pain with overhead activities, night pain, a history of trauma, or sports participation. It is also helpful to ask about numbness, tingling, burning, or weakness, as this may suggest a cervical radiculopathy or brachial plexopathy. A medical history significant for diabetes or thyroid disease may increase suspicion for calcific tendinopathy.

A thorough physical examination is also important when evaluating a patient with shoulder pain. The examination should begin with inspection and palpation of the painful shoulder. Active and passive range of motion of the shoulder should also be assessed. Manual muscle testing should be done to assess for weakness that may be related to pain inhibition, a rotator cuff tear, or neurological injury. Sensation and reflexes should also be assessed if nerve damage is suspected. Finally, provocative tests should be done.

Tests classically used to assess shoulder pain related to subacromial impingement include the Hawkin's impingement test, Neer's sign test, and Yocum's test. These maneuvers all have in common the idea that when performed correctly the subacromial space is compressed. For all of the above impingement tests, reproducible pain with the maneuver is considered a positive sign. In the Hawkin's test, the shoulder is passively flexed to 90 degrees and internally rotated by the examiner. In the Yocum's test, the patient places their hand on the contralateral 
shoulder and elevates their elbow without elevating the shoulder in the process. The Neer's sign test is performed by passively forward flexing an internally rotated shoulder. ${ }^{17}$

Occasionally, a patient will have constitutional symptoms of fever and malaise. ${ }^{4}$ In these patients, elevated inflammatory markers may be found on blood work such as C-reactive protein (CRP), erythrocyte sedimentation rate (ESR), and serum white blood count (WBC). ${ }^{4}$ In these patients it is important to consider septic arthritis, gout, and pseudogout. Ultimately, to make the diagnosis of calcific tendinopathy of the rotator cuff, imaging studies will be needed.

\section{Imaging studies}

Plain films are often adequate to diagnose calcific tendinopathy of the rotator cuff. Anteroposterior, outlet view, internal rotation, and external rotation views are routinely ordered (Fig.1). Magnetic resonance imaging (MRI) can be a useful adjunct study to see if there is an associated rotator cuff tear and to evaluate for suspected osteolysis of the greater tuberosity. In addition, MRI has a distinct advantage for evaluation of the glenoid labrum, subcortical bone, and deep soft tissues when compared to other imaging modalities.

Ultrasound has become another useful tool for evaluating sources of shoulder pain, with comparable sensitivities to magnetic resonance imaging when performed by a skilled ultrasonographer. ${ }^{18,19}$ Additionally, ultrasound allows the ultrasonographer to perform a dynamic evaluation to assess for subacromial impingement. Another advantage of ultrasound is that the resolution from the 
transducer is better than that from magnetic resonance imaging, on the order of 200 $\mu \mathrm{m}$ with current technology. ${ }^{19}$

More specifically, ultrasound has been shown to be an effective tool to diagnose calcific tendinopathy and has been shown to have the ability to identify even small calcific lesions. ${ }^{20}$ In addition, two separate studies showed that a positive Doppler signal within calcific deposits correlated with a patient having pain.21,22 Clinically, this could help determine if the calcification is the cause of a patient's pain or just an incidental finding.

On ultrasound, the calcium deposits will usually have a hyperechoic appearance often with acoustic shadowing noticeable on exam (Fig. 2). ${ }^{23}$ The calcification may also appear isoechoic, and an amorphous calcification will replace the normal fibrillar appearance of a tendon. ${ }^{23,24}$ Typically, the calcifications will be found on ultrasound exam along the fibrillar appearing tendon fibers. Frequently, they appear linearly along the tendon fiber, but may at times appear globular or amorphous if the calcification is not well-formed yet.23,24 Ultrasound may also pick up cortical bony erosions, which may help with prognosis.

\section{Treatment Options}

\section{Medications}

Non-steroidal anti-inflammatory drugs (NSAIDs) are a common treatment for many painful conditions. This class of medications inhibits cyclooxygenase- 1 and cyclooxygenase-2 (COX-1 and COX-2) enzymes, which are important in the inflammatory cascade that produces prostaglandins and thromboxanes. They are frequently used to help treat pain associated with subacromial bursitis, rotator cuff 
tendonitis and other causes of shoulder pain, including calcific tendinopathy. Although no studies have focused on what medication regimen is optimal, it is reasonable to treat patients symptomatically with NSAIDs.

Caution should always be used when prescribing NSAIDs to patients with a history of gastrointestinal (GI) or cardiac disease. Upper GI complications, including bleeding, have been found to be increased using NSAIDs versus placebo. ${ }^{25}$ NSAIDs, as a class, have been associated with increased risk of vascular events as well, including myocardial infarction and stroke.25-27

Yokoyama et al looked at using histamine blockade to reduce the symptoms associated with calcific tendinopathy. The rationale for using this class of medication was the decrease in serum calcium seen in patients with hyperparathyroidism treated with a histamine blocker. Sixteen patients who failed conservative treatment were treated with cimetidine for 3 months. Results showed reduced VAS scores, decreased impairment of shoulder movement, and radiologic evidence of decreased calcium deposit size compared to pre-treatment. ${ }^{28}$ Although the mechanism is unclear, in this small sample size, cimetidine appears to have benefited these patients.

Other medications to consider include Tramadol (Ultram) or rarely shortacting narcotics. These may be considered in patients who are having difficulty sleeping secondary to moderate to severe pain.

\section{Modalities}

Multiple modalities have been utilized in the treatment of RCCT, including iontophoresis, therapeutic ultrasound, and extracorporal shock wave therapy. 
Acetic acid iontophoresis (AAI) was first described in the treatment of calcific tendinosis in $1955 .{ }^{29}$ More recently, multiple randomized controlled trials have been performed to analyze the effectiveness of this modality. The theory is that using acetic acid will acidify the environment around the calcium depositions. Since most calcium crystals are made of hydroxyapatite crystals, the depositions should, in theory, dissolve in this environment. Iontophoresis is used to help direct the medication to deeper tissues. Two recent studies failed to show improvement with AAI in the treatment of RCCT. One study compared AAI with no treatment, and found improvement in the area and density of the calcium deposits of both groups at the end of the study compared to pre-treatment, but no difference between groups. ${ }^{30}$ Similarly, Leduc et al found improvements in pain, range of motion and number of calcium deposits from the beginning of the study to after the treatment period, both in those receiving AAI and those receiving sham treatment. ${ }^{31}$ Time, with or without physiotherapy, appeared to improve patients' symptoms in these studies. Larger studies may be needed to show benefit, but at this time it is difficult to recommend the use of AAI in the treatment of RCCT.

\section{Therapeutic ultrasound}

Therapeutic ultrasound may be used for painful musculoskeletal disorders, and was looked at specifically in treating RCCT in one study in the New England Journal of Medicine in 1999. Investigators treated patients with pulsed therapeutic ultrasound for 24 sessions over 6 weeks and found both decreased pain and improved quality of life when compared to sham ultrasound. ${ }^{32}$ These results were 
significant at the end of the study, but the effects were no longer statistically significant at the 9-month follow up.

\section{Extracorporal shock wave therapy}

Extracorporal shock wave therapy (ESWT) is a modality that is often used to break up urologic calcium stones and has recently been investigated in RCCT. One group in Italy found a decrease in pain, increase in function and associated decrease in calcium deposit size after four treatments with ESWT compared to sham therapy. ${ }^{33}$ These findings were significant immediately after treatment and at one and six months post-treatment.

Another study looked at long-term results for patients who received ESWT for RCCT. In this study group, most of the patients received a single treatment $(\mathrm{n}=$ 27), while others received two $(n=9)$ or three $(n=3)$ treatment sessions. At 6-month follow-up, the treatment group had decreased pain, increased power, motion and activity when compared to the control group. ${ }^{34}$ Calcium deposit size was also noted to be decreased in the study group, with no difference in the control group. When

following these patients 2 years post-treatment, $90.9 \%$ of patients had significant, if not complete, improvement in shoulder symptoms. This study, however, had a very small control group and patients were not blinded to treatment group.

Rebuzzi compared ESWT to arthroscopic surgery, and found no difference between groups in functional improvement or pain reduction. ${ }^{35}$ No other studies that we are aware of directly compare non-operative treatments to each other, or to surgery. 
ESWT is often not covered by insurance companies and the cost to the patient may range from $\$ 100-\$ 1000$ per treatment session. It is often noted to be a painful procedure for patients.

\section{Physical Therapy}

The conservative management of shoulder pain related to RCCT usually involves a formal physical therapy program. Range of motion exercises and improving scapular mechanics can benefit patients with calcific tendinopathy. There are no available studies that outline a specific therapy protocol for patients with RCCT. However, there are many studies that look at subacromial impingement, a common sequelae of RCCT.

Scapular dyskinesis, abnormal position and movement of the scapula, can contribute to shoulder pain due to subacromial impingement. ${ }^{36}$ Patients may feel their shoulder "catch" during abduction or flexion of the glenohumeral joint. This dynamic impingement can arise from anatomic (coracohumeral ligament thickening, calcium deposition, acromial spurring) or functional (abnormal muscle firing pattern, weak scapular stabilizers) reasons. Injury to or abnormal function of the rotator cuff muscles, which are dynamic stabilizers of the glenohumeral joint, will alter the positioning of the humeral head relative to the glenoid. Most commonly, the humerus will be more cephalad, which will decrease the subacromial space as the humerus flexes or abducts. The larger and more powerful scapular rotators, including the trapezius, rhomboids, levator scapula, latissimus dorsi and serratus anterior, are active to varying amounts throughout scapulothoracic and glenohumeral overhead motion. ${ }^{37}$ If these muscles are not coordinated properly in 
their muscle firing pattern, acromial elevation will not be adequate as the humerus rotates, which may also lead to impingement symptoms. If you combine functional decreased subacromial space with a calcific deposit in the rotator cuff, you are further reducing the space that tendons can move under the acromion without restriction. Therefore, therapy should be directed at regaining optimal scapular mechanics, which will allow for better clearance of the supraspinatus tendon and subacromial bursa between the humeral head and anterior portion of the acromion.

Beneficial exercises have been identified which preferentially activate the middle trapezius, lower trapezius and serratus anterior, with less activation of upper trapezius. ${ }^{38}$ These exercises can help restore proper balance of the scapular rotators. A well organized therapy program, starting from range of motion and flexibility exercises, progressing to closed-chain, then open-chain and finally sports specific exercises has been shown to lead to improved scapular mechanics and related shoulder pain. ${ }^{39}$

\section{Injections}

Various injections with differing techniques have been utilized in the management of RCCT. An intrabursal injection of corticosteroid may be used if the patient has symptoms of subacromial impingement and bursitis. ${ }^{3}$ Other injection techniques attempt to address the calcium deposit more directly by breaking up and aspirating its contents.

One study used fluoroscopy to help needle guidance during aspiration and lavage of calcium deposits. They were able to aspirate calcium in $76 \%$ of the patients, and while calcium deposits were decreased in area at 2-month follow-up, 
no difference was seen between patients with positive or negative aspiration of calcium..$^{40}$ Pain and range of motion were improved, although the authors questioned the clinical significance of the amount of range of motion gained. Multiple groups have investigated lavage techniques under real-time ultrasound guidance to aspirate portions of the calcium deposits. These techniques may utilize two needles $24,41,42$ or one. ${ }^{43-48}$ The technique is often performed as follows (Fig. 3 and 4):

Under ultrasound guidance, the needle is introduced in plane with the ultrasound beam, allowing visualization of the needle throughout its path to the calcium deposit. Most investigators stress puncturing the deposit once (or twice if using the two-needle technique), to maintain the integrity of the calcium deposit capsule and reduce calcium leakage. In the singleneedle technique, once inside the calcium deposit, a small amount of fluid is injected and then pressure on the plunger is released to allow back flow of calcium deposit into the syringe. In the two-needle technique, the second needle aspirates the introduced fluid. Often, a cloudy fluid containing calcium will be removed. This process is repeated until the aspirated fluid is clear and the calcium deposit appears smaller on ultrasound images. Once aspirated fluid is clear, or if no cloudy fluid could be removed, the deposit is needled repeatedly in attempt to break up the remaining calcium deposit.

At that point, the needle is either drawn back into the subacromial bursa, or is completely withdrawn and a new needle is inserted into the subacromial bursa. A corticosteroid injection, with local anesthetic, is then administered to prevent subsequent bursitis. 
Farin was the first to describe outcomes when using ultrasound guidance to perform aspiration and lavage of calcium deposits. In their 2-needle technique, they punctured the deposit 10-15 times prior to injecting saline solution, followed by aspiration of the injected fluid with a second needle until no more calcium could be removed. Results were excellent in $73 \%$ of patients, and often correlated with decreased size of the deposit. ${ }^{49}$

Another two-needle technique did not include the calcium puncture prior to the lavage portion of the procedure. This step was omitted to maintain the cavity as intact as possible, which was assumed to facilitate more effective calcium removal. They found improved pain using both the Constant and VAS scales in the treated compared to non-treated group at 1, 3, and 12 months post procedure, an effect that disappeared at 5- and 10-year follow-up. ${ }^{41}$

In an attempt to achieve better calcium salt dissolution, Scofienza recently investigated the variable of saline temperature. They found shorter procedure time and easier dissolution of calcium deposits. ${ }^{42}$ VAS was not different between saline temperature groups, but bursitis incidence was less in warm saline treated patients.

Other investigators utilize only a single needle, which further reduces the number of times the calcium cavity is violated. Bradley et al presented a case report of 11 patients with RCCT treated with this technique. By two weeks post-procedure, 10 of the patients had complete resolution of symptoms. ${ }^{43}$ The one patient with pain remaining had a concurrent supraspinatus tendon tear. 
Yoo presented data from 35 shoulders that were treated with needle decompression via a similar technique described above. Twenty-five shoulders were almost pain free by 6 months post-procedure, and 22 experienced relief by 3 months. ${ }^{47}$ Six of the patients needed to undergo arthroscopic removal due to persistent pain and were found to have rotator cuff defects at the time of surgery.

Ciampi treated 50 patients with calcium deposit puncture prior to lavage and aspiration. At 3-month follow up; pain was significantly improved when using the SPADI score, UCLA score and VAS scale. ${ }^{48}$

At the Hospital for Special Surgery in New York, investigators retrospectively looked at 36 patients who had undergone either single or double needle aspiration followed by lavage for calcific tendinopathy. Both the NRS score and L'Insalata scores improved post-procedure, and $77.8 \%$ of the patients rated their level of satisfaction as "good", "very good", or "excellent". ${ }^{50}$ Four patients ended up receiving surgical treatment after the procedure.

One study investigated the difference between ESWT alone or with the addition of needling. While both groups had improvement in Constant shoulder scores, the group who received ESWT and needling had better clinical improvement, radiologic disappearance of deposits, and less need for arthroscopic surgery. ${ }^{51}$

One of the limitations of many of these studies is the lack of a control group. As is well documented, calcific tendinopathy is a dynamic process that is often selflimiting and spontaneous resorption of the deposits may occur. Comparing patients pre- and post-procedure is good to track, but without a control group, it is 
impossible to say how much of the benefit is due to the treatment chosen or to spontaneous improvement that would have occurred without any intervention.

The specific technique used in these studies varied. A few important aspects were consistent between all of the studies:

- Calcium deposit fragmentation

- Lavage of calcium deposit with saline +/- lidocaine

- Attempted aspiration of calcium.

- Subacromial bursa injection to reduce the risk of post-procedure bursitis While calcium removal is the goal of these procedures, it can't always be accomplished. Ultrasound and computed tomography images can help predict if calcific deposits will be hard and unable to aspirate or soft and able to remove calcium during needle treatment. ${ }^{24}$ The ability to aspirate calcium may be dependent on the phase of the calcification $24,43,44$, and deposit type might play a role in successful treatment. ${ }^{47}$ The ability to remove more calcium during the procedure does not result in better pain relief ${ }^{42}$ and a decrease in calcium deposit size is seen regardless of initial ability to remove all calcium from the deposit. ${ }^{43,45}$ Removal of calcium may not even be necessary to provide pain relief. ${ }^{52}$

\section{Conclusions}

RCCT is a common finding in rotator cuff disease that can cause significant shoulder pain and disability. It usually presents as an acute tendonitis with subacromial impingement and bursitis. It can be seen easily with imaging studies such as x-ray, MRI, or ultrasound. Most patients respond favorably to conservative measures. NSAIDs, modalities, and subacromial bursa steroid injections can help 
manage pain. Physical therapy can help improve scapular mechanics and decrease subacromial impingement. Therapeutic ultrasound, ESWT and ultrasound-guided needle aspiration and lavage can reduce the size of the calcium deposit and lead to substantial long-term improvement in pain and function. 


\section{Summary Tables}

Table 1. Summary of different theories on pathogenesis of calcific tendinopathy

\begin{tabular}{|l|l|}
\hline Theory & Proposed Mechanism \\
\hline Degenerative Calcification & $\begin{array}{l}\text { Intracellular calcium accumulated from old, } \\
\text { damaged and necrotic tenocytes }\end{array}$ \\
\hline Reactive Calcification & $\begin{array}{l}\text { Metaplastic fibrocartilage with calcium } \\
\text { deposited through an inflammatory mechanism }\end{array}$ \\
\hline Endochondral Ossification & $\begin{array}{l}\text { Metaplastic fibrocartilage becomes vascular } \\
\text { from underlying bone marrow and calcium } \\
\text { deposited without evidence of inflammation } \\
\text { (Similar to bone spur formation) }\end{array}$ \\
\hline Chondral Metaplasia & $\begin{array}{l}\text { Erroneous differentiation of tenocytes into bone } \\
\text { cells, mediated by BMP-2 }\end{array}$ \\
\hline
\end{tabular}

Table 2. Summary of different stages of calcific tendinopathy

\begin{tabular}{|l|l|}
\hline Stages of calcification & Pathophysiology \\
\hline Pre-calcific stage & $\begin{array}{l}\text { Tenocytes undergo metaplasia into } \\
\text { fibrocartilagenous tissue }\end{array}$ \\
\hline Calcific stage - formative phase & Calcium crystals deposit onto metaplastic tissue \\
\hline Calcific stage - resorptive phase & Phagocytosis of deposited calcium \\
\hline Post-calcific stage & Remodeling of affected tissue \\
\hline
\end{tabular}




\section{References}

1. Bosworth BM. Calcium Deposits in the Shoulder and Subacromial Bursitis. Jour. A.M.A. 1941;116(22):2477-2488.

2. Oliva F, Via AG, Maffulli N. Calcific tendinopathy of the rotator cuff tendons. Sports medicine and arthroscopy review. Sep 2011;19(3):237243.

3. Uhthoff HK, Loehr JW. Calcific Tendinopathy of the Rotator Cuff: Pathogenesis, Diagnosis, and Management. The Journal of the American Academy of Orthopaedic Surgeons. Jul 1997;5(4):183-191.

4. Speed CA, Hazleman BL. Calcific tendinitis of the shoulder. The New England journal of medicine. May 20 1999;340(20):1582-1584.

5. Oliva F, Barisani D, Grasso A, Maffulli N. Gene expression analysis in calcific tendinopathy of the rotator cuff. European cells \& materials. 2011;21:548-557.

6. Harvie P, Pollard TC, Carr AJ. Calcific tendinitis: natural history and association with endocrine disorders. Journal of shoulder and elbow surgery / American Shoulder and Elbow Surgeons ... [et al.]. Mar-Apr 2007;16(2):169-173.

7. Faure G, Daculsi G. Calcified tendinitis: a review. Annals of the rheumatic diseases. Aug 1983;42 Suppl 1:49-53.

8. Oliva F, Via AG, Maffulli N. Physiopathology of intratendinous calcific deposition. BMC medicine. 2012;10:95.

9. Uhthoff HK, Sarkar K, Maynard JA. Calcifying tendinitis: a new concept of its pathogenesis. Clinical orthopaedics and related research. Jul-Aug 1976(118):164-168.

10. Brewer BJ. Aging of the rotator cuff. The American journal of sports medicine. Mar-Apr 1979;7(2):102-110.

11. Olsson 0. Degenerative changes of the shoulder joint and their connection with shoulder pain; a morphological and clinical investigation with special attention to the cuff and biceps tendon. Acta chirurgica Scandinavica. Supplementum. 1953;181:1-130.

12. Mohr W, Bilger S. [Basic morphologic structures of calcified tendopathy and their significance for pathogenesis]. Zeitschrift fur Rheumatologie. Nov-Dec 1990;49(6):346-355.

13. Benjamin M, Rufai A, Ralphs JR. The mechanism of formation of bony spurs (enthesophytes) in the achilles tendon. Arthritis and rheumatism. Mar 2000;43(3):576-583.

14. Rui YF, Lui PP, Chan LS, Chan KM, Fu SC, Li G. Does erroneous differentiation of tendon-derived stem cells contribute to the 
pathogenesis of calcifying tendinopathy? Chinese medical journal. Feb 2011;124(4):606-610.

15. Hashimoto Y, Yoshida G, Toyoda H, Takaoka K. Generation of tendon-tobone interface "enthesis" with use of recombinant BMP-2 in a rabbit model. Journal of orthopaedic research : official publication of the Orthopaedic Research Society. Nov 2007;25(11):1415-1424.

16. Porcellini G, Paladini P, Campi F, Pegreffi F. Osteolytic lesion of greater tuberosity in calcific tendinitis of the shoulder. Journal of shoulder and elbow surgery / American Shoulder and Elbow Surgeons ... [et al.]. MarApr 2009;18(2):210-215.

17. Malanga GA, Nadler S. Musculoskeletal physical examination : an evidence-based approach. Philadelphia, Pa.: Mosby; 2006.

18. Jacobson JA. Musculoskeletal ultrasound: focused impact on MRI. AJR. American journal of roentgenology. Sep 2009;193(3):619-627.

19. Levine BD, Motamedi K, Seeger LL. Imaging of the shoulder: a comparison of MRI and ultrasound. Current sports medicine reports. Sep-Oct 2012;11(5):239-243.

20. Papatheodorou A, Ellinas P, Takis F, Tsanis A, Maris I, Batakis N. US of the shoulder: rotator cuff and non-rotator cuff disorders. Radiographics : a review publication of the Radiological Society of North America, Inc. Jan-Feb 2006;26(1):e23.

21. Chiou HJ, Chou YH, Wu JJ, Hsu CC, Huang DY, Chang CY. Evaluation of calcific tendonitis of the rotator cuff: role of color Doppler ultrasonography. Journal of ultrasound in medicine : official journal of the American Institute of Ultrasound in Medicine. Mar 2002;21(3):289295; quiz 296-287.

22. Le Goff B, Berthelot JM, Guillot P, Glemarec J, Maugars Y. Assessment of calcific tendonitis of rotator cuff by ultrasonography: comparison between symptomatic and asymptomatic shoulders. Joint, bone, spine : revue du rhumatisme. May 2010;77(3):258-263.

23. Jacobson JA. Fundamentals of musculoskeletal ultrasound. Philadelphia, PA: Saunders/Elsevier; 2007.

24. Farin PU. Consistency of rotator-cuff calcifications. Observations on plain radiography, sonography, computed tomography, and at needle treatment. Investigative radiology. May 1996;31(5):300-304.

25. Coxib, traditional NTC, Bhala N, et al. Vascular and upper gastrointestinal effects of non-steroidal anti-inflammatory drugs: metaanalyses of individual participant data from randomised trials. Lancet. Aug 31 2013;382(9894):769-779.

26. Kearney PM, Baigent C, Godwin J, Halls H, Emberson JR, Patrono C. Do selective cyclo-oxygenase-2 inhibitors and traditional non-steroidal anti-inflammatory drugs increase the risk of atherothrombosis? Metaanalysis of randomised trials. Bmj. Jun 3 2006;332(7553):1302-1308.

27. Trelle S, Reichenbach S, Wandel S, et al. Cardiovascular safety of nonsteroidal anti-inflammatory drugs: network meta-analysis. Bmj. 2011;342:c7086. 
28. Yokoyama M, Aono H, Takeda A, Morita K. Cimetidine for chronic calcifying tendinitis of the shoulder. Regional anesthesia and pain medicine. May-Jun 2003;28(3):248-252.

29. Psaki CG, Carroll J. Acetic acid ionization; a study of determine the absorptive effects upon calcified tendinitis of the shoulder. The Physical therapy review. Feb 1955;35(2):84-87.

30. Perron M, Malouin F. Acetic acid iontophoresis and ultrasound for the treatment of calcifying tendinitis of the shoulder: a randomized control trial. Archives of physical medicine and rehabilitation. Apr 1997;78(4):379-384.

31. Leduc BE, Caya J, Tremblay S, Bureau NJ, Dumont M. Treatment of calcifying tendinitis of the shoulder by acetic acid iontophoresis: a double-blind randomized controlled trial. Archives of physical medicine and rehabilitation. Oct 2003;84(10):1523-1527.

32. Ebenbichler GR, Erdogmus CB, Resch KL, et al. Ultrasound therapy for calcific tendinitis of the shoulder. The New England journal of medicine. May 20 1999;340(20):1533-1538.

33. Cosentino R, De Stefano R, Selvi E, et al. Extracorporeal shock wave therapy for chronic calcific tendinitis of the shoulder: single blind study. Annals of the rheumatic diseases. Mar 2003;62(3):248-250.

34. Wang CJ, Yang KD, Wang FS, Chen HH, Wang JW. Shock wave therapy for calcific tendinitis of the shoulder: a prospective clinical study with twoyear follow-up. The American journal of sports medicine. May-Jun 2003;31(3):425-430.

35. Rebuzzi E, Coletti N, Schiavetti S, Giusto F. Arthroscopy surgery versus shock wave therapy for chronic calcifying tendinitis of the shoulder. Journal of orthopaedics and traumatology : official journal of the Italian Society of Orthopaedics and Traumatology. Dec 2008;9(4):179-185.

36. Burkhart SS, Morgan CD, Kibler WB. The disabled throwing shoulder: spectrum of pathology Part III: The SICK scapula, scapular dyskinesis, the kinetic chain, and rehabilitation. Arthroscopy : the journal of arthroscopic \& related surgery : official publication of the Arthroscopy Association of North America and the International Arthroscopy Association. Jul-Aug 2003;19(6):641-661.

37. Bagg SD, Forrest WJ. A biomechanical analysis of scapular rotation during arm abduction in the scapular plane. American journal of physical medicine \& rehabilitation / Association of Academic Physiatrists. Dec 1988;67(6):238-245.

38. Cools AM, Dewitte V, Lanszweert F, et al. Rehabilitation of scapular muscle balance: which exercises to prescribe? The American journal of sports medicine. Oct 2007;35(10):1744-1751.

39. Kibler WB, McMullen J. Scapular dyskinesis and its relation to shoulder pain. The Journal of the American Academy of Orthopaedic Surgeons. Mar-Apr 2003;11(2):142-151. 
40. Pfister J, Gerber $\mathrm{H}$. Chronic calcifying tendinitis of the shoulder-therapy by percutaneous needle aspiration and lavage: a prospective open study of 62 shoulders. Clinical rheumatology. May 1997;16(3):269-274.

41. Serafini G, Sconfienza LM, Lacelli F, Silvestri E, Aliprandi A, Sardanelli F. Rotator cuff calcific tendonitis: short-term and 10-year outcomes after two-needle us-guided percutaneous treatment--nonrandomized controlled trial. Radiology. Jul 2009;252(1):157-164.

42. Sconfienza LM, Bandirali M, Serafini G, et al. Rotator cuff calcific tendinitis: does warm saline solution improve the short-term outcome of double-needle US-guided treatment? Radiology. Feb 2012;262(2):560-566.

43. Bradley M, Bhamra MS, Robson MJ. Ultrasound guided aspiration of symptomatic supraspinatus calcific deposits. The British journal of radiology. Jul 1995;68(811):716-719.

44. Bureau NJ. Calcific tendinopathy of the shoulder. Seminars in musculoskeletal radiology. Feb 2013;17(1):80-84.

45. del Cura JL, Torre I, Zabala R, Legorburu A. Sonographically guided percutaneous needle lavage in calcific tendinitis of the shoulder: shortand long-term results. AJR. American journal of roentgenology. Sep 2007;189(3):W128-134.

46. Saboeiro GR. Sonography in the treatment of calcific tendinitis of the rotator cuff. Journal of ultrasound in medicine : official journal of the American Institute of Ultrasound in Medicine. Oct 2012;31(10):15131518.

47. Yoo JC, Koh KH, Park WH, Park JC, Kim SM, Yoon YC. The outcome of ultrasound-guided needle decompression and steroid injection in calcific tendinitis. Journal of shoulder and elbow surgery / American Shoulder and Elbow Surgeons ... [et al.]. Jun 2010;19(4):596-600.

48. Ciampi PV, M. Ultrasound-Guided Percutaneous Needle Aspiration of Rotator cuff Calcifications. Medicina e chirugia orthopedica numero uno. 2011(Marzo/aprile):67-69.

49. Farin PU, Rasanen $H$, Jaroma $H$, Harju A. Rotator cuff calcifications: treatment with ultrasound-guided percutaneous needle aspiration and lavage. Skeletal radiology. Aug 1996;25(6):551-554.

50. Lin JT, Adler RS, Bracilovic A, Cooper G, Sofka C, Lutz GE. Clinical outcomes of ultrasound-guided aspiration and lavage in calcific tendinosis of the shoulder. HSS journal : the musculoskeletal journal of Hospital for Special Surgery. Feb 2007;3(1):99-105.

51. Krasny C, Enenkel M, Aigner N, Wlk M, Landsiedl F. Ultrasound-guided needling combined with shock-wave therapy for the treatment of calcifying tendonitis of the shoulder. The Journal of bone and joint surgery. British volume. Apr 2005;87(4):501-507.

52. Zhu J, Jiang Y, Hu Y, Xing C, Hu B. Evaluating the long-term effect of ultrasound-guided needle puncture without aspiration on calcifying supraspinatus tendinitis. Advances in therapy. Nov 2008;25(11):12291234. 
